\title{
BLICKDIAGNOSE
}

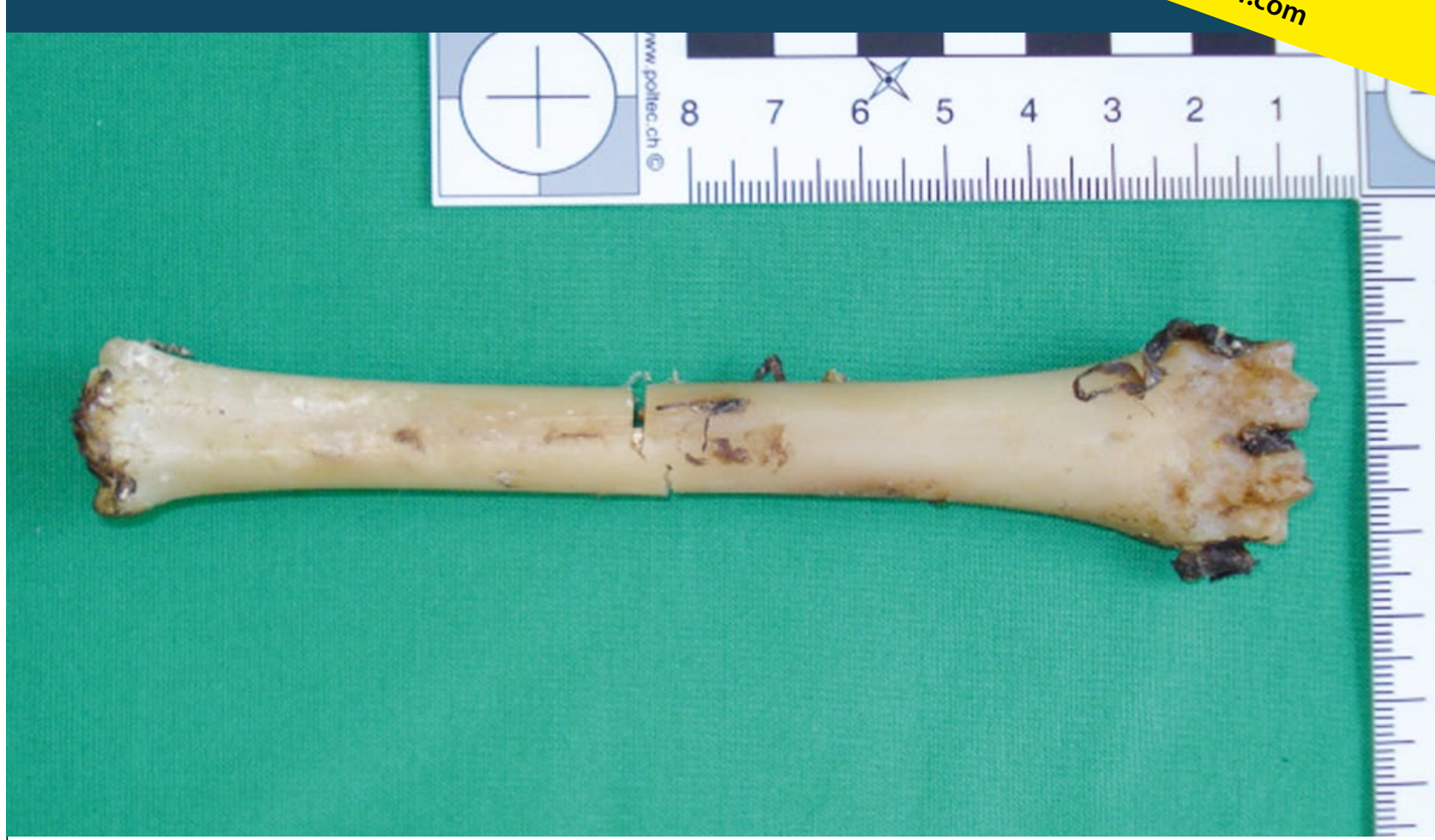

Kapitalverbrechen vermutet

\section{Ein außergewöhnlicher Säuglingsknochen}

\section{Wegen des Verdachts auf ein Gewaltverbre- chen wurde obiger Knochen zu einer regio- nalen Polizeidienststelle gebracht. Der zustän- dige Polizeivertragsarzt hegte den Verdacht auf einen Säuglingsknochen und empfahl zur weiteren Abklärung ein rechtsmedizinisches Gutachten.}

— Dem $15 \mathrm{~cm}$ langen und bis zu $3 \mathrm{~cm}$ breiten Röhrenknochen hafteten zahlreiche bräunliche Weichteilreste an, die einen verwesungsartigen Geruch verströmten. Der Knochen glänzte speckig und zeigte endständig mehrere, mit spitzem Werkzeug beigebrachte Verletzungen. Die fehlenden Epiphysenfugen konnten das Vorliegen eines Säuglingsknochens schnell widerlegen. Anhand der Knochenmorphologie, insbesondere des auffälligen Rollhügels (rechts im Bild), konnte auch ein menschlicher Ursprung des Knochens ausgeschlossen werden.

Die anhaftenden Weichteilreste und die mit spitzem Werkzeug beigebrachten Verletzungen verlieren ihre kriminalistische Relevanz, wenn man weiß, dass es sich bei diesem Knochen um einen so genannten „echten Kauknochen“ für Hunde mit entsprechenden Bissspuren handelt. Der inzwischen weitestgehend abgekaute Büffellederbezug erklärt den auffälligen, speckigen Glanz der Knochenoberfläche und den verwesungsartigen Geruch.

Keywords: long bone, chewing bone, capital crime

- Dr. med. Benno Hartung, Prof. Dr. med. Wolfgang Huckenbeck, Institut für Rechtsmedizin, Universitätsklinikum Düsseldorf, Moorenstraße 5, D-40225 Düsseldorf

\section{Weitere Infos auf springermedizin.de}

Weitere Fälle unserer Leser finden Sie im Internet unter: - www.springermedizin.de/blickdiagnose 